\title{
Expression of HOXDIO Gene in Normal Endometrium and Endometrial Adenocarcinoma
}

\author{
Janet Osborne, MD, Changzi Hu, MD, Colleen Hawley, BS, Lowell J. Underwood, BS, \\ Timothy J. O'Brien, PhD, and Vicki V. Baker, MD
}

\begin{abstract}
OBJECTrvE: Hox genes encode DNA transcription regulatory proteins that contain a conserved 61 amino acid protein called the homeodomain. Although best known for their role in cellular differentiation during embryonic development, aberrant expression of these genes has been associated with hematologic and solid neoplasms. The purpose of this study was to determine the relative expression of HOXD10 in human endometrial adenocarcinomas.

METHODS: $\quad m R N A$ was isolated from 7 normal endometrial specimens and 28 endometrial adenocarcinoma specimens. CDNA was synthesized using random hexamer primers. The expression of HOXD10 relative to $\beta$-tubulin (internal control) was assessed by densitometric comparison of co-amplified Phosphorus-32 $\left(^{32} P\right.$ ) labeled gene products separated by agarose gel electrophoresis. Direct sequencing of purified HOXD10 polymerase chain reaction product was also performed.

RESUlTs: The sequence of the purified HOXD10 product corresponds to the known DNA sequence reported in the National Institutes of Health Gene Bank. $m R N A$ expression of HOXD10 relative to $\beta$-tubulin is significantly lower in endometrial carcinomas than in normal endometrium. Furthermore, the ratio of HOXD10 to $\beta$-tubulin expression varies inversely with the histologic grade of the tumor $(\mathrm{P}=.0009)$.

CONCLUsion: Cancer is a multistep process involving the aberrant expression of genes that regulate cell growth and differentiation. Human HOXD10 gene expression is altered in endometrial carcinoma and varies with the histologic grade of differentiation. This observation supports the theory that homeobox genes play a role in oncogenesis. (J Soc Gynecol Invest 1998;5:277-280) Copyright (C) 1998 by the Society for Gynecologic Investigation.
\end{abstract}

KEY WORDS: Homeobox genes, HOXD10, oncogenesis, endometrial cancer.

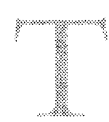

he homeobox is a 183 base pair DNA sequence that is highly conserved among species. ${ }^{1-3}$ Although first identified in Drosophila genes that control embryonic development, homeobox genes have been found in virtually all eukaryotes. ${ }^{4-6}$ The homeobox encoded 61 amino acid homeodomain is the DNA binding domain of a much larger homeotic protein. The secondary structure of the homeodomain allows it to bind specific DNA sequences and act as a transcription modulator. ${ }^{3}$ As demonstrated in Drosophila species and mouse embryonic development, homeotic gene products regulate target genes in a precise spatial and temporal pattern and are responsible for providing the correct information for cellular differentiation along the rostral-caudal axis of the embryo. ${ }^{1,7}$ By standard nomenclature the term "Hox" refers to mammalian homeobox genes related to Drosophila species's HOM-C genes, and uppercase letters are used to designate

From the Division of Gynecologic Oncology, University of Michigan, Ann Arbor. Michigan and Departments of Obstetrics and Gynecology, and Biochemistry and Molecular Biology, University of Arkansas for Medical Sciences, Little Rock, Arkansas.

Funded in part by the American Cancer Sociery Clinical Oncology Fellowship Award, grant $95-781$.

Address correspondence and reprint requests to: Janet $1 .$. Osborne, MD, Lehigh Valley Women's Cancer Center. 1011 Pond Road, Allentown, PA 18104.

Copyright 1998 by the Society for Gynecologic Investigation.

Published by Elsevier Science Inc. human gene names. ${ }^{8,9}$ In humans and mice, 38 HOM-C/ HOX genes are organized in 13 paralog groups located on four different chromosomes. ${ }^{9,10}$

Homeobox genes are also expressed in normal adult tissues and may play a role in maintaining the differentiated state. ${ }^{11-13}$ Expression of the 38 clustered HOX genes has been studied in kidney, lung, colon, and liver. Patterns of expression are specific for each organ. Furthermore, differences in the expression of HOX genes between normal and carcinomatous tissues exist. ${ }^{12,13}$ HOX genes also affect regulation of hematopoietic cell line differentiation. ${ }^{14}$ Altered expression has been associated with some types of leukemia. ${ }^{14-16}$ HOXD10 is strongly expressed in uterine tissue and to a lesser extent in other adult tissues of the urogenital tract. ${ }^{11,17}$ The purpose of this study was to determine the relative expression of HOXD10 in human endometrial carcinomas.

\section{MATERIALS AND METHODS}

\section{Tissue Samples}

Endometrial tissue samples were obtained through the institution's tissue procurement core from 7 patients undergoing 
hysterectomy for benign gynecologic disorders and 28 patients undergoing hysterectomy for the treatment of endometrial cancer: grade $1(n=7)$, grade $2(n=10)$, and grade $3(n=11)$. Histologic grade was assigned by the International Federation of Gynecology and Obstetrics (FIGO) criteria and was obtained from coded pathology reports to protect patient confidentiality. Tissue samples were promptly frozen in liquid nitrogen and stored at $-80 \mathrm{C}$.

\section{mRNA Isolation and DNA Synthesis}

mRNA was directly isolated from frozen tissue samples by using a Mini Ribosep Ultra mRNA Isolation Kit (Becton Dickinson Labware, Bedford, MA). This protocol allows poly $A+$ rich mRNA to be extracted from the tissue lysate by utilizing affinity chromatography media $\mathrm{Oligo}(\mathrm{dT})$ cellulose. $^{18}$ The amount of mRNA recovered was estimated by ultraviolet spectrophotometry. ${ }^{19}$ cDNA was synthesized by reverse transcription of $5-\mu \mathrm{g}$ mRNA with random hexamer priming using GeneAmp RNA PCR Kit (Perkin Elmer, Newark, NJ) at 42C for 60 minutes.

\section{Primer Construction}

Oligonucleotide primer pairs were designed to cross one intron-exon splice site so that genomic DNA amplification could be detected. The primer sequences were selected according to DNA sequences described by Redline et $\mathrm{al}^{11,17}$ for HOXI 10 and Lee et $\mathrm{al}^{20}$ for $\beta$-tubulin. The National Institutes of Health (NIH) Gene Bank was searched using BLAST, and no other genes were identified with matching oligonucleotide sequences. The primer sequences are as follows: HOXD10 sense, 5-TCCCGAAGTGCAGGAGAAGC-3; HOXD10 antisense, 5-CCTCTGACCGGCCTGAGAC-3; $\beta$-tubulin sense, 5-CCAGATCTTTAGACCAGACAAC-3; $\beta$-tubulin antisense, 5-TTGCGGAGGTCAGCATTGAG-3.

\section{Quantitative Polymerase Chain Reaction}

Quantitative polymerase chain reaction (PCR) using reagents from GeneAmp RNA PCR Kit was performed independently from cDNA synthesis. To evaluate the consistency of our results, PCR was performed in duplicate on separate days. The PCR mixture contained cDNA derived from $0.1-\mu \mathrm{g}$ mRNA, 25 pmol of sense and antisense primers for both HOXD 10 and $\beta$-tubulin genes, $50 \mu \mathrm{M}$ of each dNTPs, $2 \mu \mathrm{ci}$ of $\left[\alpha-{ }^{32} \mathrm{P}\right] \mathrm{dCTP}, 0.5 \mathrm{U}$ of Taq DNA polymerase and reaction buffer in a final volume of $25 \mu \mathrm{L} .^{21-23}$ The target sequences were amplified in parallel with the $\beta$-tubulin gene as an internal control. Twenty-five cycles of PCR were conducted using a PTC-100 thermal cycler (MJ Research, Watertown, MA). The first five cycles included denaturation at $95 \mathrm{C}$ for 1 minute, primer annealing at $6 \overline{5} \mathrm{C}$ for 1 minute, and extension at $72 \mathrm{C}$ for 30 seconds. The subsequent 2() cycles used the same denaturation step, but used an annealing temperature of $60 \mathrm{C}$ and added 1 second per cycle to the extension phase.

The PCR products were separated by electrophoresis on a $2 \%$ agarose gel using $0.5 \times$ trisboric acid EDTA rumning buffer. $^{24}$ After drying the gels, autoradiographs were developed on
Kodak X-omatic film (Rochester, NY). Densitometry was measured using AMBIS QuantProbe software (Ambis, San Diego, CA).

\section{Statistical Analysis}

The ratio of HOXD10 to $\beta$-tubulin expression for each sample was calculated. Statistical significance was determined by the Kruskal-Wallis test, a nonparametric equivalent of analysis of variances by ranks. The data were also evaluated by analysis of variance with Scheffe's F test for post-hoc multiple comparisons. Ratios from the duplicate PCR data sets were compared by paired Student $t$ test.

\section{DNA Sequencing}

The PCR-amplified HOXD10 product from a normal endometrial tissue sample was separated on a $3 \%$ low melting agarose gel. The band was isolated and purified using Wizard PCR Preps DNA Purification System (Promega, Madison, WI). The sequencing reaction was carried out using fmol DNA Sequencing System (Promega) end-labeled primer protocol. The sequencing products were then separated on a $8 \%$ polyacrylamide urea gel.

\section{RESULTS}

To confirm that the PCR product represents HOXD10, DNA sequencing of a normal specimen was performed. The oligonucleotide sequence of our purified PCR product corresponds to human HOXD10) as reported in the NIH Gene Bank. ${ }^{11}$ To compare expression of HOXD10 in normal and neoplastic endometrial tissues, the target gene was co-amplified with $\beta$-tubulin as an internal standard. $\beta$-Tubulin was consistently expressed in normal and carcinomatous specimens. The amplification of both products is linear through 30 cycles. The present study used 25 cycles in comparing HOXD10 with $\beta$-tubulin expression.

The relative expression of the HOXD10 gene was examined in 7 normal endometrial tissues, 7 grade 1, 10 grade 2, and 11 grade 3 endometrial carcinomas (Figure 1). The expression of $\mathrm{HOXD10}$ relative to $\beta$-tubulin varies significantly between the histologic groups as shown in Table $1(P=.0009)$. HOXD10 expression varies inversely with the histologic grade of the tumor. Scheffé's F test for post-hoc multiple comparisons demonstrates that statistically significant differences exist between normal endometrium and grade 2 and grade 3 carcinomas. Statistical analysis of the duplicate data set gave similar results (data not shown). Comparison of the two data sets by paired $t$ test showed no significant difference $(P>.10)$. Two of 10 grade 2 and 2 of 11 grade 3 specimens did not have detectable expression of HOXD10. A normal level of expression was found in one atypical hyperplasia specimen that was not included in the analysis. Figure 2 illustrates $\beta$-tubulin and HOXD10 expression in nomal and carcinomatous endometrial tissue samples. 


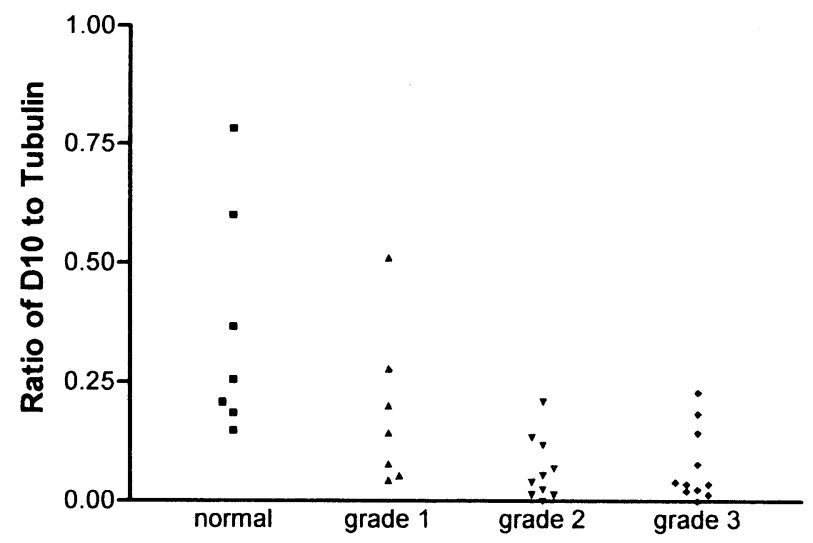

Figure 1. Expression of HOXD10 relative to $\beta$-tubulin in normal endometrium and endometrial carcinoma. Expression of HOXD10 is significantly lower in grade 2 and 3 endometrial carcinoma when compared with normal endometrial tissue.

\section{DISCUSSION}

Regulation of cell proliferation, cell specialization, organogenesis, and apoptosis are necessary for proper development of a multicellular organism. Homeobox genes play a critical role as master control genes that regulate the development of higher organisms. ${ }^{1,2,5-8,25}$ Although the precise molecular interactions underlying activation and function of homeobox genes are not yet completely understood, in vitro and in vivo sturdies have demonstrated that homeodomain proteins function as DNA-dependent transcription regulators. ${ }^{25,26}$

Cancer is a disease characterized by defective regulation of cell growth. Inherent in the property of HOX genes as regulators of transcription is their potential involvement in aberrant gene expression contributing to oncogenesis. Kongsuwan et $\mathrm{al}^{1 \mathrm{t}}$ found a high expression of HoxB8 (formerly 2.4) due to a proviral insertion, intracisternal-A particle (IAP), upstream from the HoxB 8 promoter in murine WEHI-3B myeloid leukemia cells. Aberdam et $\mathrm{al}^{27}$ tested the oncogenic potential of HOX genes by transfecting NIH 3 T3 fibroblast cells with the IAP activated HoxB8 gene that was cloned from the WEHI-3B cells. Transfected fibroblasts exhibited altered morphology, loss of contact inhibition, and accelerated cell division. Nude mice injected with the transfected cells developed fibrosarcomas and succumbed within 4 to 6 months. Another homeobox gene, PBX (formerly Prl), is associated

Table 1. Mean Ratio and Ranks of HOXD10 and $\beta$-Tubulin Expression in Normal Endometrium and Endometrial Cancer Specimens

\begin{tabular}{lrcc}
\hline Tissue type & $\boldsymbol{n}$ & HOXD10 ratio* & Mean rank \\
\hline Normal & 7 & $.4118 \pm .1094$ & 29.857 \\
Grade 1 & 7 & $.1948 \pm .0559$ & 22.286 \\
Grade 2 & 10 & $.0872 \pm .0284^{\ddagger}$ & 13.700 \\
Grade 3 & 11 & $.0627 \pm .0209^{\ddagger}$ & 11.636 \\
\hline
\end{tabular}

* Values are expressed as mean \pm standard error of the mean.

t Statistically evaluated by Kruskal- Wallis test: $\mathrm{H}=16 .(011)(P=.00(19)$.

F Scheffés $F$ test shows statistically significant difference in the ratio mean between these groups and normal endonetrium $(P=.0125$ and . o(1)9, respectively).

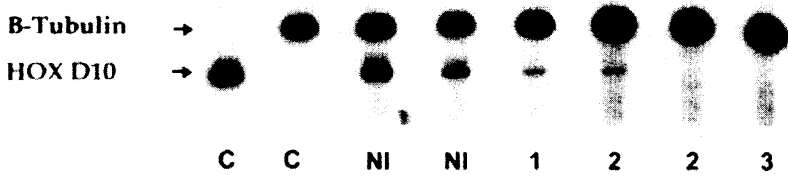

Figure 2. Autoradiograph made from dried gel of separated polymerase chain reaction products illustrating the expression of $\beta$-tubulin and HOXD10 genes in normal endometrium and endometrial carcinoma specimens. The reaction mixture used in the controls contains primers for a single gene and cDNA from a normal endometrial specimen. $\mathrm{C}=$ control; $\mathrm{Nl}=$ normal endometrium; $1,2,3=$ histologic grades.

with $\mathrm{t}(1 ; 19)$ translocation in human pre-B cell acute lymphoblastic leukemia. ${ }^{28}$

Altered HOX gene expression has been demonstrated in solid neoplasms as well. Cilio et $\mathrm{al}^{12.29}$ analyzed the expression of the 38 clustered HOX genes in normal and neoplastic renal tissue. Thirty of the 38 genes were expressed in normal kidney. Similar analyses were performed in colon, lung, and liver. Each tissue was found to have a complex pattern of expression characteristic of that organ. ${ }^{13,28}$ Loss of expression of one or more HOX genes was observed in neoplastic renal and colonic tissues compared with normal tissue from the same patient, suggesting that HOX gene transcription factors may play a role in carcinogenesis. ${ }^{12,13,29}$

To our knowledge, the complete expression pattern of the HOX gene complex has not been determined for endometrial tissue. However, Redline et $\mathrm{a}^{11,17}$ found strong expression of HOXD10 in human and murine endometrial tissues. Human cervical tissue only weakly expressed HOXD10 and no expression was found in ovarian tissue. Only a subset (6 of 11) of endometrial adenocarcinomas expressed HOXD 10 , and overall the expression was weaker than in normal specimens. ${ }^{17}$ The present study corroborates the findings of decreased expression of HOXD10 in endometrial carcinomas compared with normal endometrium. Furthermore, we determined that the relative expression of HOXD10 varied inversely with the grade of histologic differentiation and was statistically significant, particularly between normal endometrial tissue and histologic grade 2 and 3 carcinomas. The amount of tissue available limited our study to performing reverse transcriptase-PCR as a semiquantitative measurement of gene transcription. Northern blots or immunohistochemical staining would strengthen our findings, but because there is no commercially available monoclonal antibody and RNA was limited these approaches were not possible. However, several studies, including Shigemasa et $\mathrm{al}^{30}$ that examined $\mathrm{p} 16$ expression in ovarian neoplasms confirmed good correlation between those techniques and results of reverse transcriptase-PCR. Our data are consistent with others studies of solid neoplasms showing loss of HOX gene expression in carcinomas relative to normal tissue and support the hypothesis that HOX genes may act as tumor suppressor genes functioning to maintain a differentiated phenotype in neoplasms. ${ }^{29.31}$ At this time there is insufficient evidence to make that conclusion. An alternative explanation is that 
decreased HOXD 10 transcripts in poorly differentiated carcinomas may only be a consequence of oncogenic transformation. Further investigation is needed to evaluate the association of aberrant expression of HOX genes and their role in oncogenesis.

\section{REFERENCES}

1. McGinnis W, Levine MS, Hafen E, Kuroiwa A, Gehring WJ. A conserved DNA sequence in homoeotic genes of the Drosophila antennapedia and bithorax complexes. Nature 1984;308:428-33.

2. Gehring WJ. Homeoboxes in the study of development. Science 1987:236:1245-52.

3. Scott MP, Tamkum JW, Hartzell GW. The structure and function of the homeodomain. Biochem Biophys Acta (Rev Cancer) 1989;989:25-32.

4. Acampora D, D'Esposito M, Faiella A, et al. The human Hox gene family. Nucleic Acids Res 1989;17:10385-402.

5. Shashikant CS, Utset MF, Violette SM, et al. Homeobox genes in mouse development. Crit Rev Eurkaryotic Gene Expression 1991;1:207-45.

6. Shepherd JC, McGinnis W, Carrasco AE, De Robertis EM, Gehring WJ. Fly and frog homeo domains show homologies with yeast mating type regulatory type proteins. Nature 1984; 310:70-7.

7. Duboule D, Dolle P. The structural and functional organization of the murine Hox gene family resembles that of Drosophila homeotic genes. EMBO J 1989;8:1497-505.

8. Akam M. HOX and HOM: Homologous gene clusters in insects and vertebrates. Cell 1989;57:347-49.

9. Scott MP. Vertebrate homeobox gene nomenclature. Cell 1992 71:551-3.

10. Boncinelli E, Acampora D. Pannese $M$, et al. Organization of human class I homeobox genes. Genome 1989;31:745-56.

11. Redline RW, Williams AJ, Patterson P, Collins T. Human HOX $+E$ : A gene strongly expressed in the adult male and female urogenital tracts. Genomics 1992;13:425-30.

12. Cillo C, Barba G, Freschi G, Bucciarelli MC, Magli MC, Boncinelli $\mathrm{E}$. Hox gene expression in normal and neoplastic human kidney. Int J Cancer 1992:51:892-7.

13. De Vita G, Barba P. Odartchenko N, et al. Expression of homeobox-containing genes in primary and metastatic colorectal cancer. Eur J Cancer 1993;29A:887-93.

14. Kongsuwan K, Webb E, Housiaux P. Adams JM. Expression of multiple homeobox genes within diverse mammalian haematopoietic lineages. EMBO J 1988;7:2131-39.

15. Blatt C, Aberdam D, Schwartz R, Sachs L. DNA rearrangement of a homeobox gene in myeloid leukaemic cells. EMBO J 1988;7:4283-90

16. Kongsuwan K, Allen J, Adams JM. Expression of Hox-2.4 homeobox gene directed by proviral insertion in a mycloid leukemia. Nucleic Acids Res 1989:17:1881-92.

17. Redline RW, Hudock P, MacFee M, Patterson P. Expression of AbdB-type homeobox genes in human tumors. Lab Invest 1994; 71:663-70.

18. Badley JE, Bishop GA, St John T, Frelinger JA. A simple rapid method for the purification of poly A RNA. Biotechniques $1988 ; 6: 114-6$

19. Sambrook J, Fritsch EF, Maniatas T, eds. Molecular cloning: A laboratory manual, 2nd ed. Cold Spring Harbor, New York: Cold Spring Harbor Laboratory Press, 1989:E.5.

20. Lee MG, Lewis SA, Wilde CD, Cowam NJ. Evolutionary history of a multigene family: An expressed human beta-tubulin gene and three processed pseudogenes. Cell 1983;33:477-87.

21. Wang AM, Doyle MV, Mark DF. Quantitation of mRNA by the polymerase chain reaction. Proc Natl Acad Sci 1989;86: 9717-21

22. Kawasaki ES, Wang AM. Detection of gene expression. In: Erlich HA, ed. PCR technology: principles and applications of DNA amplification. New York: Stockton Press, 1989:89-97.

23. Saiki RK, Gelfand DH, Stoffel S, et al. Primer directed enzymatic amplification of DNA with thermostable DNA polymerase. Science 1988;239:487-91.

24. Sambrook J, Fritsch EF, Maniatas T, eds. Molecular cloning: A laboratory manuel, 2nd ed. Cold Spring Harbor, New York: Cold Spring Harbor Laboratory Press, 1989:6.3-6.9.

25. Gehring WJ, Affolter M, Burglin T. Homeodomain proteins. Annu Rev Biochem 1994;63:487-536.

26. Deschamps J. Meijlink F. Mammalian homeobox genes in normal development and neoplasia. Crit Rev Oncogen 1992;3:11773.

27. Aberdam D, Negreanu V, Sachs L, Blatt C. The oncogenic potential of an activated Hox 2.4 homeobox gene in mouse fibroblasts. Mol Cell Biol 1991;11:554-7.

28. Kamps MP, Murre C, Sung X-H, Baltimore D. A new homeobox gene contributes to the DNA binding domain of the $t(1 ; 19)$ translocation protein in pre-B ALL. Cell 1990;60:547-55.

29. Barba P, Magli MC, Tiberio C, Cillo C. Hox gene expression in human cancers. Adv Exp Med Biol 1993;348:45-57.

30. Shigemasa K. Hu C. West CM, et al. p16 overexpression: A potential early indicator of transformation in ovarian carcinoma. J Soc Gynecol Invest 1997;4:95-102.

31. Marshall CJ. Tumor suppressor genes. Cell 1991:64:313-26. 